\title{
Study on Health Monitoring System Design of Cable-Stayed Bridge
}

\author{
Heng Lin ${ }^{1}$, Yiqiang Xiang ${ }^{1,2(凶)}$, and Yakun Jia ${ }^{1}$ \\ ${ }^{1}$ Department of Civil Engineering, Zhejiang University, Hangzhou, China \\ xiangyiq@zju.edu.cn \\ 2 Cyrus Tang Center for Sensor Materials and Applications, \\ Zhejiang University, Hangzhou, China
}

\begin{abstract}
Large civil structures such as cable-stayed bridge should be periodically inspected to ensure structural integrity. Taking the main span of Chaibu Bridge as an engineering background, this paper summarizes the monitoring strategies and designs of the structure health monitoring system. The whole layout of sensors and the components of the structure health monitoring system are discussed. The study shows the structural health monitoring systems can offer valuable information in evaluating structural integrity, durability and reliability, and ensure optimal maintenance planning and safe bridge operation.
\end{abstract}

Keywords: Cable-stayed bridge $\cdot$ Monitoring strategy $\cdot$ SHMS $\cdot$ Sensor layout

\section{Introduction}

Civil engineering structures gradually deteriorate over time due to the overloading, material aging and environmental impacts. These damages will accumulate leading to the reduction of the structural loading bearing capacity. If the damages can be early detected, it could cut economic losses and extend structure service life. Hence, it is necessary to assess structure performance level at regular interval and maintain these damages.

Nowadays, structural health monitoring system (SHMS) has been applied to the condition assessment and operational management of structures. In general, the static and dynamic response signals are acquired from different sensors system. The damage-sensitive information and fingerprint can be extracted from these measurements. Then the current state of the monitored structure will be determined by analyzing the signals. Doebling et al. (1996) obtained the modal properties of the Alamosa Canyon Bridge for modal identification by using 31 acceleration transducers in America. Abe et al. (2000) designed and established a health monitoring framework for the Hakucho Bridge to get the actual dynamic behavior and loading conditions. In order to do in-depth monitoring for the Tsing Ma Bridge, the Kap Shui Mun Bridge, and the Ting Kau Bridge, 774 sensors in seven major types were totally used to build the SHMS (Wong 2004). Xiang et al. (2003) designed a structural health monitoring and management system (SHMMS) for the Wenhui Bridge in Hangzhou. And the static and dynamic data gained by SHMMS compared with the results from the finite element method to assess work condition of the bridge. Many other structures in China and the 
world also adopts the SHMS, such as the Yellow River Highway Bridge in Shandong (Li et al. 2006), the Hangzhou Bay Bridge in Zhejiang (Liu et al. 2007), and the Jindo Bridge in Korea (Ju et al. 2015). All of these real projects show that the SHMS plays a significant role in the structure construction as well as the maintenance management in service.

Nevertheless, the SHMS is a new multi-disciplinary overlapping research area, which requires collaboration among civil, mechanical, electrical and computer information engineering. The duty of civil engineers is that analyzing some key parameters or taking some arrangement strategies to make SHMS work efficiently. Thus, this paper takes a cable-stayed bridge, named the Chaibu Bridge over the Fuchun River, as an engineering background. Based on the spatial FEM model, a scheme of SHMS has been designed for the Chaibu Bridge. The layout of sensors and the other components of the SHMS, such as the data acquisition and transmission, data management, and evaluation measurements, are discussed. The aim of this paper is to review the framework of SHMS knowledge in bridge and provide references to other structures.

\section{The Strategy of Structural Health Monitoring and Method}

\subsection{Choices of Monitoring Sensors}

For general bridge structure, the structural monitoring contents consist of four parts during the bridge operation, i.e. environmental monitoring around the bridge, loading monitoring, structural response monitoring under different loadings, and durability inspection monitoring. The relative parameters of the four parts are shown in the Fig. 1.

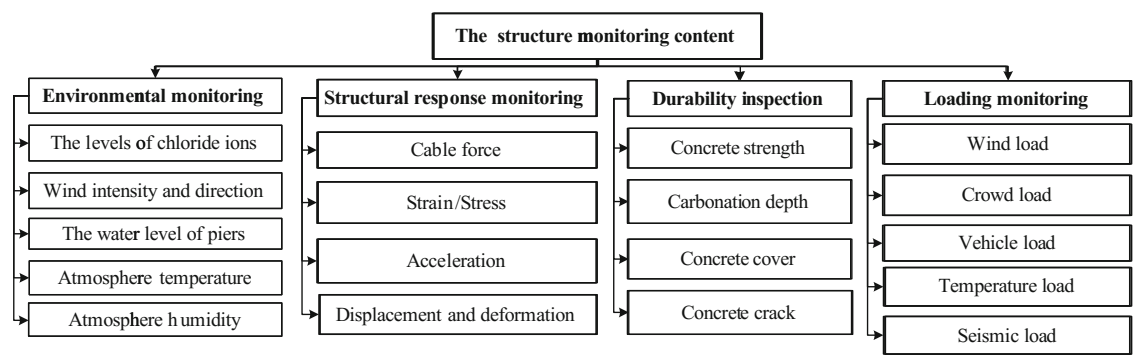

Fig. 1. The relative parameters of the structure monitoring content

As described in the Fig. 1, each part plays a unique function in the monitoring. The environmental monitoring is to record the variation of environment factors around the bridge, and analyze the influence of these factors to the structure response. The environmental factors include the direction, velocity and pressure of wind and fluid around the bridge, variation of humidity and atmosphere temperature during structure service period etc. The main work of loading monitoring is to gain traffic volume, types of vehicles, axle loads and distribution on the deck. Structural response monitoring is to measure and get values and changes of the physical parameters, such as structure 
strain/stress, crack and cracking width, deflections or displacements, tower deviation, cable forces, accelerations and mode shapes. Loading response is the most direct reflection of the structure conditions. Some characteristic parameters also can be obtained by processing the signals from the loading response monitoring. Chen et al. (2014) applied the frame work to analyze strain and displacement data from the monitoring system on the Hurley Bridge (Wisconsin Structure B-26-7), and the analysis revealed the developing trend of the strain data and evaluated the properties of materials. So the structure response monitoring is the core of the whole monitoring system. The structural durability inspection and monitoring is to obtain concrete carbonation depth, the steel bar corrosion potential of the structure, the chloride ion concentration, cover thickness and the defect of concrete, etc.

In order to monitor the above parameters, different types of sensors should be chosen or various measurement and test technologies be used to get relative physical quantities, such as strain sensor, cracking width sensor, accelerometers sensor or velocity sensor, wind velocity sensor, numerical camera analysis technology, weighing apparatus, instrument for measuring cable forces, static strain test and analysis system, and dynamical signal analysis $\&$ processing system etc.

\subsection{Some Principles for Laying Out Sensors}

The main principle is to obtain more available monitoring signals by installing sensors as reasonably as possible (Ou 2004). Some optimization algorithms are proposed to locate the sensor positions, such as genetic algorithm, serial method, and nonlinear programming method. After the monitoring parameters are identified, the number of sensors could be determined according to the size and complexity of the structure and the monitoring objectives. Based on one-year measurement data obtained from 45 accelerometers and 83 temperature sensors permanently installed on the bridge, $\mathrm{Ni}$ et al. (2004) gets the modal frequencies of the first ten modes and temperatures at different locations at one-hour intervals for deeper bridge conditions analysis.

Another principle is considering the scale of investment and structural level, because these structures often require long service life to generate social benefits and recovery costs. It means that different bridges have unique demands and characteristics. According to the budget, designers should focus on the main concerns of the bridge. Furthermore, the sensors used in the SHMS should be advancing and mature. In order to meet the requirement of information management system, instruments need to be digitalized and intelligent. It is a disturbing question that the sensor becomes degradation when the structure needs monitoring. So the sensors used in the SHMS also should be easy to replace and maintain.

\subsection{Some Method for Structural Status Damage Identification and Condition Assessment}

The important part of the SHMS is detecting possible structural damage and position, and assessing the conditions of the structure by the static and dynamic responses. These 
detection and assessment methods may be vibration-based or static-based, deterministic or statistical, linear or nonlinear, or local or global. Gentile et al. (2015) applied microwave remote sensing to measure the vibration response on the stay cables of two cable-stayed bridges, which validates that the radar technology is suitable to the SHMS. Bonessio et al. (2012) proposed a procedure to estimate existing bridge damage by installing some accelerometers. Arangio et al. (2014) made use of the Bayesian neural networks to identify the damage of the cable-stayed bridge. Several existing SHMS could detect some deterioration of the bridge by the natural frequencies and the vibration mode shapes. When the structure is complex, some researchers observe the changes in dynamic features with the numerical simulation method. By the improved integrated finite strip method, Naderian et al. (2016) derived the real dynamic properties of a long-span cable-stayed bridge considering the interactions among deck, piers, and cables. Ho et al. (2013) investigates an efficient image-based damage detection system that can automatically identify damages to the cable surface through image processing techniques and pattern recognition. So, a great effort has been devoted to the development of effective methods for identifying structure damage. Sensitive to the damage and automatic for the structure evaluation are the future developing trend of structural status identification.

\section{Bridge Background and Analysis}

\subsection{Bridge Project}

The main span of Chaibu Bridge is a two-tower cable-stayed bridge carrying six lanes of traffic over the Fuchun River, as shown in the Fig. 2. It is located on the highway between the Meirong and the Fengchuan in the Tonglu County, China. The construction of the bridge began in April 2014 and is expected to complete in December 2017. The cable stayed bridge has a total length of $412 \mathrm{~m}(106 \mathrm{~m}+200 \mathrm{~m}+106 \mathrm{~m})$.
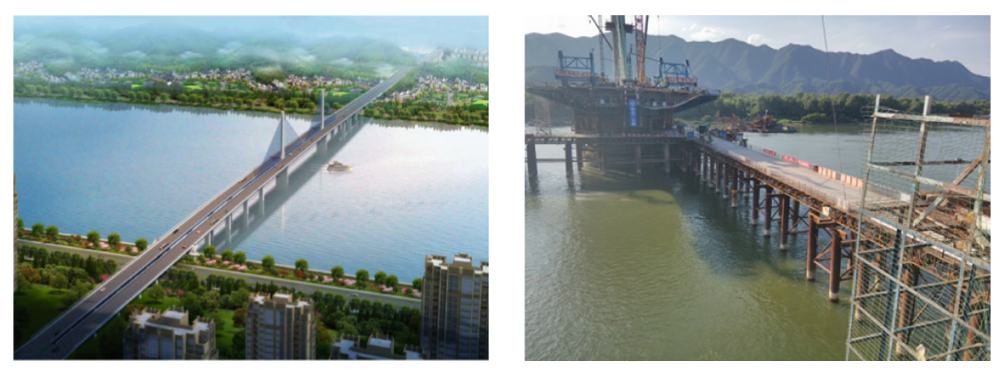

Fig. 2. Overview of the main span of ChaiBu Bridge

There are 104 cables divided into four central cable plane parts and arranged in twin towers in total. The decks are composed of cast-in-situ concrete box girder by cantilever method. Each cable tower is a single column tower, and the main tower is $64 \mathrm{~m}$ high using box-section. The pier is double thin-wall structure with rectangle section. 
The connection of bridge's girder, pylon, and pier is rigid joint. The Fig. 3 illustrates some structural details and geometrical sizes of the bridge.

\subsection{Design Features of the Main Span of Chaibu Bridge and Analysis}

The main span of Chaibu Bridge is a two-tower cable-stayed bridge, which is made of galvanized stranded wire cables, high strength concrete pylon, and single-box multi-cell girder. The galvanized stranded wire cables and box girders adopt the multi-point support method of every certain interval to connect. The dead and other live loads imposed on the main girder are transmitted to the bridge pylons through the bridge stayed cable, and the bridge pier foundation receives loading from the pylons and main girder at last. Moreover, as for statically indeterminate structure, the bridge adjusts internal stress condition by tensing the stayed cable force. Due to the cables directly anchor to the pylon, there is a P- $\Delta$ effect affecting the behavior of the pylon. The pylon become instable and the cable forces will increase or reduce rapidly if the pressure or inclination of the pylon exceeds the limit. So, the cables are the major monitoring members during the construction and operation. Besides, the Chaibu Bridge's girder, pylon, and pier are rigidly jointed, which causes the additional internal forces by the temperature effect. The piers in the main span of Chaibu Bridge takes double thin-wall piers, and it not only reduces the additional internal forces of bridge by the temperature effect and the concrete shrinkage and creep, but also save concrete material in case of no cutting the longitudinal bending stiffness of structures.

In order to deeply understand mechanical behavior of the cable stayed bridge and arrange the monitoring points accurately, structure behavior can be analyzed by the finite element model. Thus, a simplified finite element model is established on the basis of the engineering drawing by using the ABAQUS software package. As shown in the Fig. 4, the cables are simulated by using linear elastic bar elements, which consider the sag effect of cables by equivalent elastic modulus. And the main girders are simulated by grillage beam method. The cable pylon is a single column and rigidly connects with the girders and piers. Beam elements are applied to pylons, girders, and piers. Then, the boundary conditions of the model are given, according to the real constraining of the bridge. The structural material properties are listed in the Table 1. Once established analysis model and known various parameters of structural materials, structural static and dynamic behavior is easy to gain. It lays foundation for determination of monitoring physical parameters and choice of different sensors.

\subsection{Modal Analysis of the Main Span of Chaibu Bridge}

There are different methods of modal calculation, such as subspace method, block Lanczos method, power dynamics method, etc. The subspace method takes the subspace iteration technique, and calculation samples show the exactitude and efficiency of subspace method. In this paper, modal calculation adopts the subspace method, the convergence error takes default value, and the number of iterations is 30 . The first $30^{\text {th }}$ 


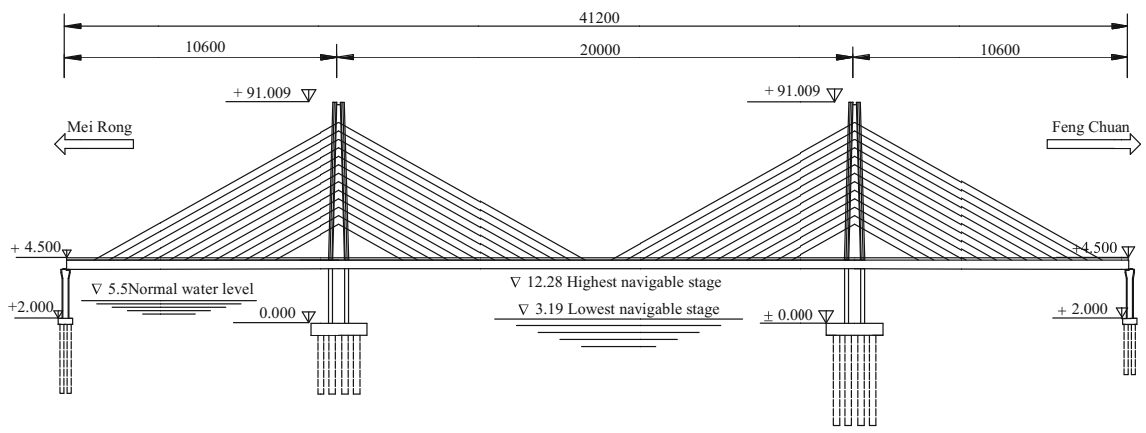

(a) Elevation view of the main span of ChaiBu Bridge
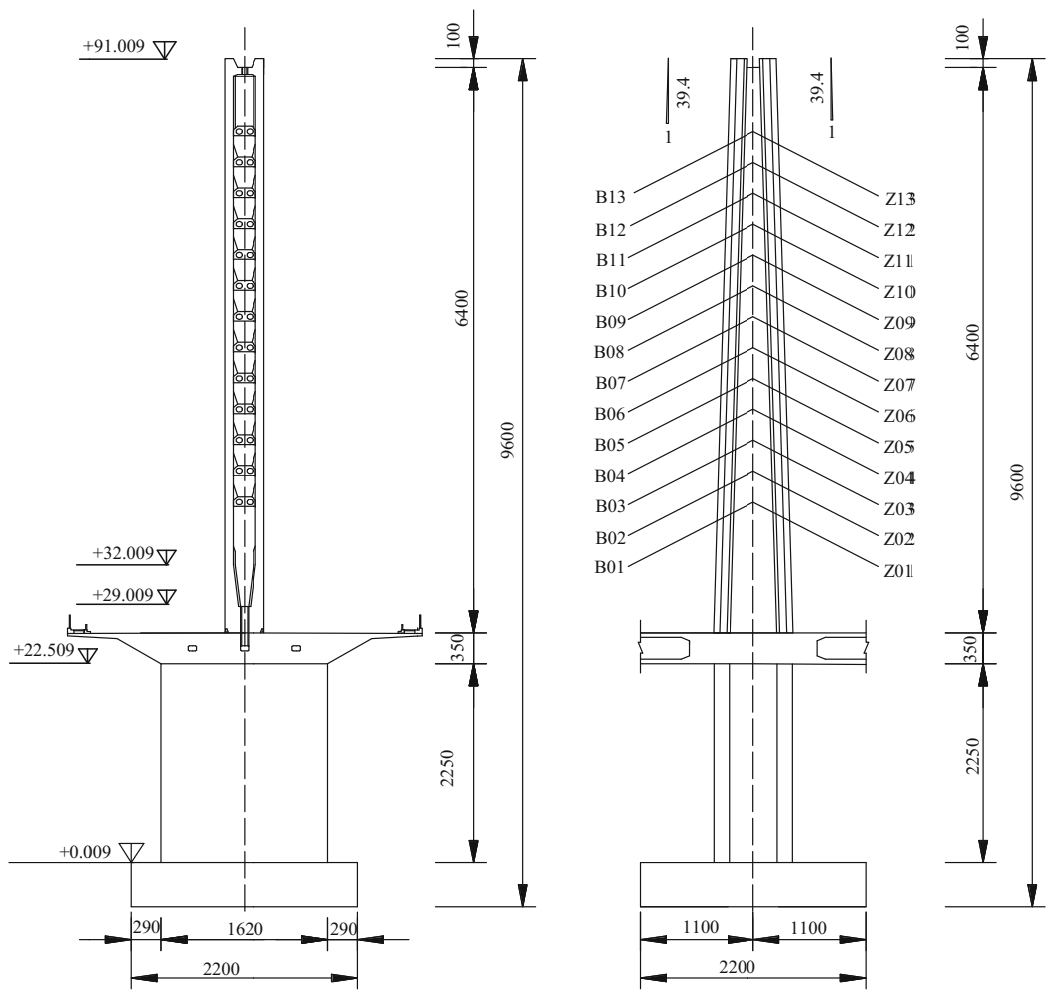

(b)Pylon and Pier of the main span of Chaibu Bridge

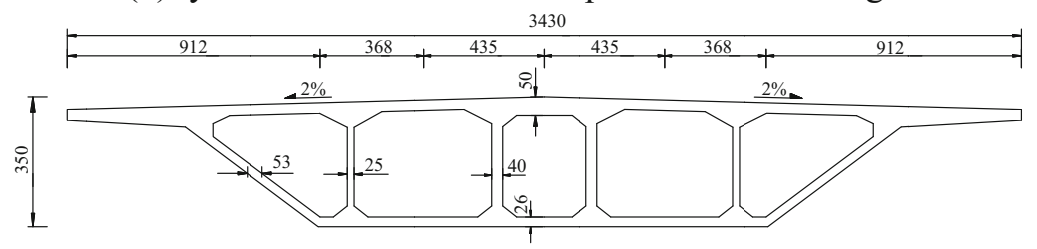

(c)Cross section of the main span of Chaibu Bridge

Fig. 3. Geometrical size of the main span of Chaibu Bridge (units:cm) 


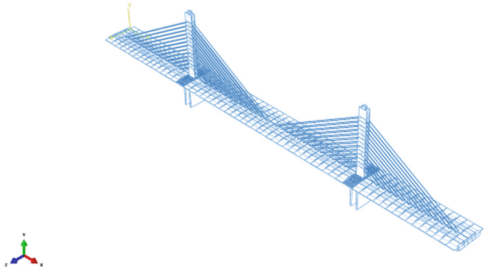

(a) Rendering

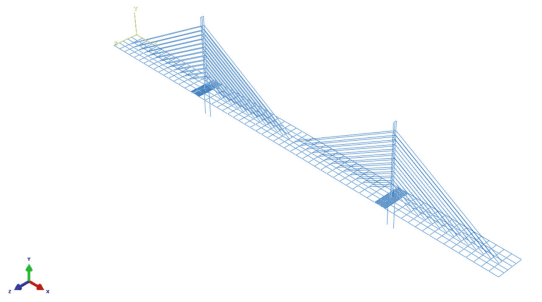

(b) Finite element model

Fig. 4. FEM of the main span Chaibu Bridge

Table 1. Material properties of the main span of ChaiBu Bridge

\begin{tabular}{l|l|l|l|l}
\hline $\begin{array}{l}\text { Structural } \\
\text { members }\end{array}$ & Material & $\begin{array}{l}\text { Elastic modulus } \\
(\mathrm{MPa})\end{array}$ & $\begin{array}{l}\text { Poisson's } \\
\text { ratio }\end{array}$ & $\begin{array}{l}\text { Density } \\
\left(\mathrm{kN} / \mathrm{m}^{3}\right)\end{array}$ \\
\hline Girder & Concrete(C50) & $3.45 \times 10^{5}$ & 0.2 & 25 \\
\hline $\begin{array}{l}\text { Bridge pylon, } \\
\text { pier }\end{array}$ & Concrete(C55) & $3.55 \times 10^{5}$ & 0.2 & 25 \\
\hline Stay cable & $\begin{array}{l}\text { Galvanized steel } \\
\text { wire }\end{array}$ & $1.95 \times 10^{5}$ & 0.3 & 78.6 \\
\hline
\end{tabular}

Table 2. The natural frequencies and mode shapes

\begin{tabular}{l|l|l|l|l|l}
\hline Mode & 1 & 2 & 3 & 4 & 5 \\
\hline Frequency & 0.24600 & 0.26694 & 0.36568 & 0.40795 & 0.42170 \\
\hline Mode & 6 & 7 & 8 & 9 & 10 \\
\hline Frequency & 0.55418 & 0.55436 & 0.69031 & 0.79395 & 0.90702 \\
\hline Mode & 12 & 16 & 20 & 25 & 30 \\
\hline Frequency & 1.05750 & 1.52500 & 2.18420 & 2.69300 & 3.29830 \\
\hline
\end{tabular}

frequencies of the bridge are listed in the Table 2 and the first $4^{\text {th }}$ modal shapes are shown in the Fig. 5.

The results are completely symmetrical or antisymmetric, which accord with the structure of the cable-stayed bridge. At first order vibration mode, the girders have been anti-symmetric torsion. Compared with other long-span cable-stayed bridge, the $1^{\text {st }}$ order frequency is 0.246 and the $30^{\text {th }}$ frequency is 3.2983 , which indicate that the main span of Chaubu Bridge is more flexible than other general bridge engineering structure. From the Fig. 5, the features of mode shapes show that girder and pylon have different deflection and longitudinal bending. Therefore, the SHMS should consider longitudinal deformation when installing monitoring sensors. 


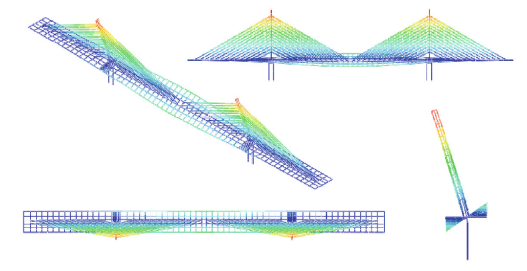

(a) $1^{\text {st }}$ vibration mode

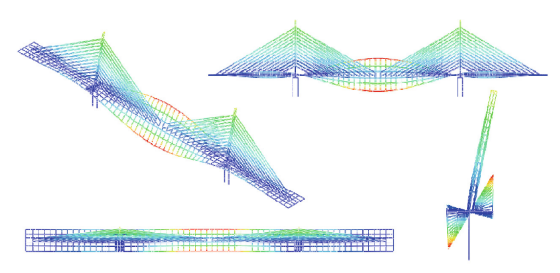

(c) $3^{\text {rd }}$ vibration mode

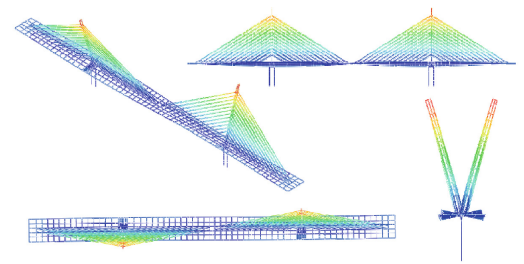

(b) $2^{\text {nd }}$ vibration mode

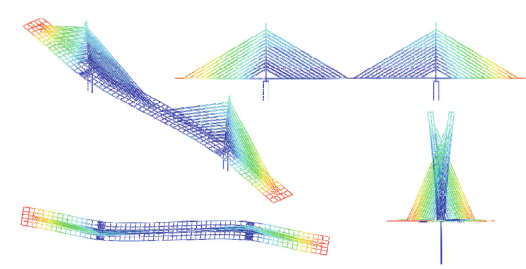

(d) $4^{\text {th }}$ vibration mode

Fig. 5. First four order vibration modes of the main span of Chaibu Bridge

\section{The SHMS of the Main Span of Chai Bridge}

The relationship between the static and dynamic response and condition of the structure is pretty tight. A SHMS is established for the main span of Chaibu Bridge by analyzing physical parameters of the bridge and installing different sensors on the bridge. The whole SHMS consists of four subsystems, including sensor subsystem, data acquisition and transmission subsystem, database management subsystem, detection and evaluation subsystem. Different subsystems play different roles and coordinate with each other during the operation.

\subsection{Sensor Subsystem}

In general, a bridge need to install various sensors to monitor physical parameters, e.g. global positioning system (GPS), air temperature and relative humidity sensors (RHS), optical fiber strain sensors (OFSS), deflectometers of hydraulic pipes (DHP), optical fiber sensors with temperature (OFST), weigh-in-motion system (WIM), one-direction accelerometers (ACC), bi-direction accelerometers (BD ACC), tri-direction accelerometers (TD ACC). The types of sensors are carefully selected such that performance can meet the requirement of the measurement range, sampling rate, sensitivity. As one of the local structural response signals, strain is very sensitive to damages of bridge. In recent years, optical fiber optic strain sensors have been extensively studied and validated to obtain high performance (Ou 2003). So the optical fiber strain sensors are used to monitor the changes of strain. Additionally, WIM, ACC, and GPS are installed on the bridge to measure the load of different vehicles, acceleration and displacement signals of structure in time domain. In this monitoring system, AER is 
established to record the atmosphere temperature and humidity for gaining the change law of some physical parameters and revising the test data. The Fig. 6 shows the details of sensors layout and the Table 3 lists the number of sensors.

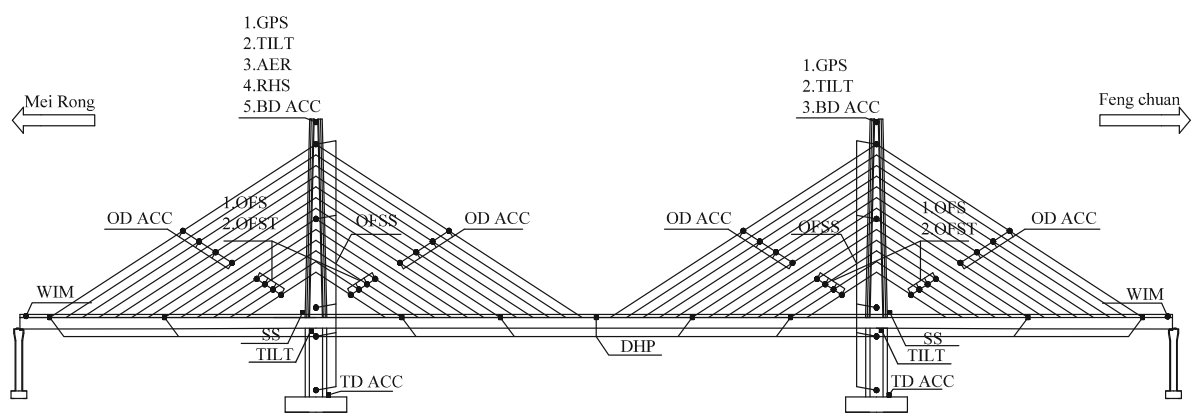

GPS: Global positioning system AER: aerovane BD ACC: Bi-direction accelerometer TD ACC: Tri-direction accelerometer

OFST: Optical fiber sensor with temperature TILT: tiltmeter RHS: air temperature and relative humidity OFS: Optical fiber sensor

WIM: weigh-in-motion system SS: sub-station OFSS: Optical fiber strain sensor DHP: Deflectometer hydraulic pipe

(a) Layout of sensors on elevation view

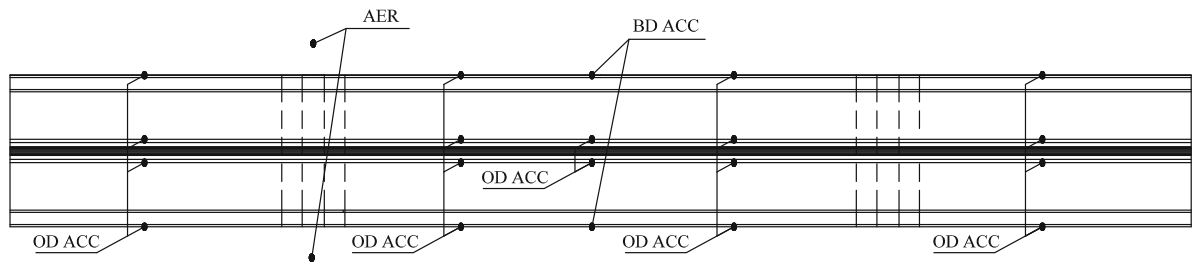

AER: aerovane OD ACC: One-direction accelerometer BD ACC: Bi-direction accelerometer

(b) Layout of accelerometers

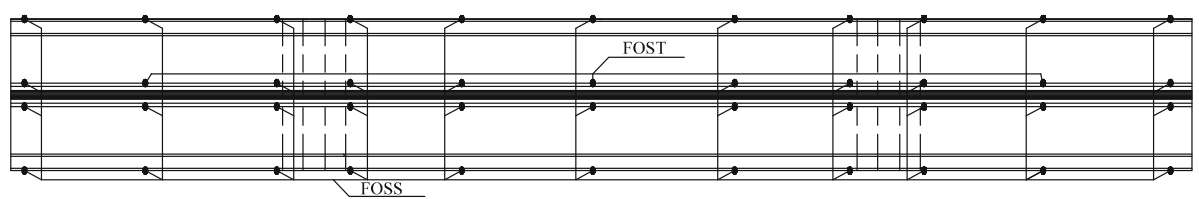

OFSS: Optical fiber strain sensor OFST: Optical fiber sensor with temperature

(c) Layout of optical fiber sensors

Fig. 6. Details of sensors layout

\subsection{Data Acquisition and Transmission Subsystem}

Data acquisition and transmission subsystem are the process of data collecting, signals processing, and long distance transmission. According to the types of sensors, 
Table 3. Layout of different sensors

\begin{tabular}{|c|c|c|c|c|}
\hline Parts & Parameters & Type of sensors & $\begin{array}{l}\text { Location of } \\
\text { installation }\end{array}$ & Number \\
\hline \multirow[t]{3}{*}{$\begin{array}{l}\text { Environment } \\
\text { monitoring }\end{array}$} & Wind field & Aerovane & $\begin{array}{l}\text { Tower top, bridge } \\
\text { deck }\end{array}$ & 3 \\
\hline & $\begin{array}{l}\text { Temperature } \\
\text { field }\end{array}$ & $\begin{array}{l}\text { Optical fiber } \\
\text { sensor with } \\
\text { temperature }\end{array}$ & Girder, cable, tower & 19 \\
\hline & Humidity & $\begin{array}{l}\text { Air relative } \\
\text { humidity }\end{array}$ & Tower top & 1 \\
\hline \multirow[t]{2}{*}{$\begin{array}{l}\text { Load } \\
\text { monitoring }\end{array}$} & Vehicle load & $\begin{array}{l}\text { Weigh-in-motion } \\
\text { system }\end{array}$ & Approach bridge & 6 \\
\hline & Strain/Stress & $\begin{array}{l}\text { Optical fiber } \\
\text { strain }\end{array}$ & $\begin{array}{l}\text { Abutment, } 1 / 4,1 / 2, \\
\text { and } 3 / 4 \text { of main span, } \\
1 / 2 \text { of side span }\end{array}$ & 54 \\
\hline \multirow{8}{*}{$\begin{array}{l}\text { Structural } \\
\text { response } \\
\text { monitoring }\end{array}$} & Disp. of tower & GPS & Tower top & 2 \\
\hline & $\begin{array}{l}\text { Deflection of } \\
\text { girder }\end{array}$ & $\begin{array}{l}\text { Deflectometer of } \\
\text { Hydraulic pipe }\end{array}$ & $\begin{array}{l}\text { Abutment, } 1 / 4,1 / 2, \\
\text { and } 3 / 4 \text { of main span, } \\
1 / 2 \text { of side span }\end{array}$ & 9 \\
\hline & Inclination & Tiltmeter & Tower top, pier top & 4 \\
\hline & \multirow[t]{3}{*}{$\begin{array}{l}\text { Acceleration of } \\
\text { towers, girders, } \\
\text { and piers }\end{array}$} & $\begin{array}{l}\text { One-direction } \\
\text { accelerometers }\end{array}$ & $\begin{array}{l}1 / 4,1 / 2, \text { and } 3 / 4 \text { of } \\
\text { main span, } 1 / 2 \text { of side } \\
\text { span }\end{array}$ & 18 \\
\hline & & $\begin{array}{l}\text { Bi-direction } \\
\text { accelerometer }\end{array}$ & $\begin{array}{l}\text { Tower top, } 1 / 2 \text { of } \\
\text { main span }\end{array}$ & 4 \\
\hline & & $\begin{array}{l}\text { Tri-direction } \\
\text { acceleration }\end{array}$ & Pier foundation & 2 \\
\hline & \multirow[t]{2}{*}{ Cable forces } & Accelerometer & Long cable & 32 \\
\hline & & Optical fiber & Short cable & 32 \\
\hline \multicolumn{4}{|c|}{ Total of measurement points } & 186 \\
\hline
\end{tabular}

monitoring signals can be divided into the optical signal or the electrical signal. Moreover, the monitoring signals also can be divided into static and dynamic signals by the frequency of signals. Based on distributed static signal with RS485 serial bus, the input/output $(\mathrm{I} / \mathrm{O})$ data acquisition system is designed. As for the high sampling rate dynamic sensors, it takes the IEEE1588 standard to ensure the acquisition system clock synchronization. The distributed data acquisition system uses industrial Ethernet for Dynamic signals transmission. Besides, LabVIEW, a product of NI Inc., USA, is selected to be the software to write the program for the collection of sensor signals.

At present, the signal transmission technologies can be classified into two categories that are the wired transmission and the wireless transmission. In this SHMS, these two signal transmission technologies are combined for transferring. Firstly, the signals like OFSS and OFST are transmitted to the industrial computer installed on the bridge by wired transmission technologies. And then the data transmit to the server installed in the station building by wireless transmission technology. 


\subsection{Database Management Subsystem}

During the monitoring process, it involves so many signals information to be stored and transmitted. Therefore, it is very important to efficiently manage the measured signals and data. A database based on the SQL Server 2008 is developed as a module of this SHMS. The entire database is composed of the static and dynamic database. The static database is used for storing static information, e.g. geography information of the bridge site, detailed design information of the bridge, layout of sensors. The dynamic database is related to the dynamic sampling rate. To prevent the shortage of the memory, some measures should be taken for database management when the memory comes to a threshold set by bridge manager. Meantime, computer-user interface designs for interactive requirements based on $\mathrm{B} / \mathrm{S}$ model. Because the $\mathrm{B} / \mathrm{S}$ model interface lowers the requirement of client configuration and improves systems operability. Some safety means are used in the SHMS to prevent intrusion of the database, such as password, virus resistance. The connection between different subsystems is shown in the Fig. 7.

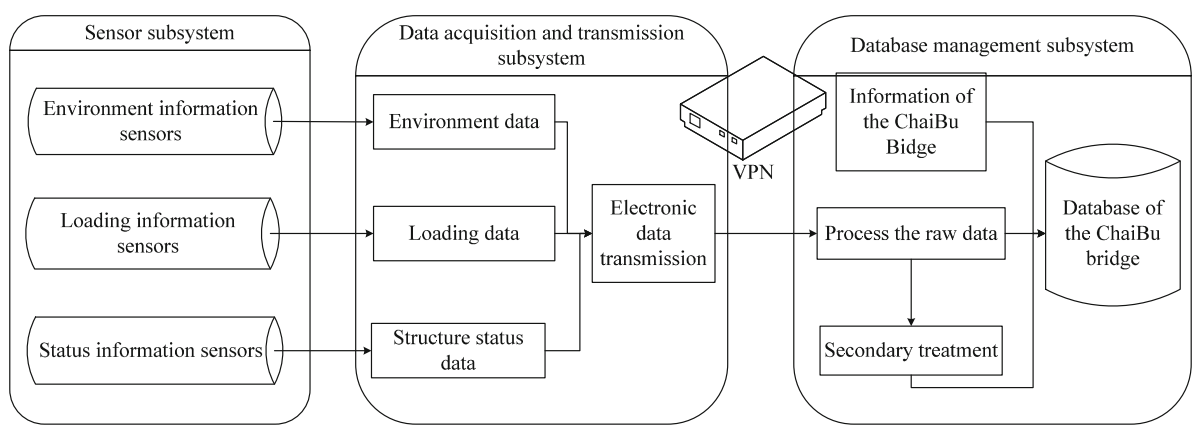

Fig. 7. The connections between different subsystems

\subsection{Detection and Evaluation Subsystem of Structural Condition}

The detection and evaluation subsystem in the SHMS is to detect damage and evaluate the condition of the bridge. The typical damage detection methods, such as frequency response model, modal curvature method, and data fusion technique for damage detection, are integrated into this subsystem and can be automatically operated by utilizing the measured data. As for the FEM, the sensitivity analysis method is employed to automatically update the FEM. For example, material elastic modulus and pre-stressed force will change with time. With several iterative cycles, the FEM could be used for analyzing the structure condition. 


\section{Conclusions}

Taking the Chaibu Bridge as an engineering background, this paper summarizes the monitoring strategies and designs of the structure healthy monitoring system. The layout of sensors and the components of the SHMS, such as the data acquisition and transmission, data management, and evaluation measurements are discussed in detail. The conclusions can be drawn as follows: (I) Sensor subsystem is the important part of the SHMS. According to the strategy, it is necessary to combine structural condition assessment method with the types of sensors to design the sensors subsystem. (II) Structure dynamic behavior test and analysis may provide so much global information in the SHMS to help us detect damage and assess current condition of the structure. Structural health monitoring systems can offer valuable information in evaluating structural integrity, durability and reliability, and ensure optimal maintenance planning and safe bridge operations. With the establishment of an appropriate design, the SHMS would produce enormous benefits for both economy and society.

Acknowledgments. This research is financially supported by the National Science Foundation of China (No. 51279178, No. 51541810) and the Cyrus Tang Foundation of China.

\section{References}

Abe, M., Fujino, Y., Yanagihara, M., et al.: Monitoring of Hakucho Suspension Bridge by ambient vibration measurement. In: Proceedings of SPIE - The International Society for Optical Engineering (2000). doi:10.1117/12.387815

Arangio, S., Bontempi, F.: Structural health monitoring of a cable-stayed bridge with Bayesian neural networks. Struct. Infrastruct. Eng. (2014). doi:10.1080/15732479.2014.951867

Bonessio, N., Lomiento, G., Benzoni, G.: Damage identification procedure for seismically isolated bridges. Struct. Control Health Monit. (2012). doi:10.1002/stc.448

Chen, Y., Corr, D.J., Durango-Cohen, P.L.: Analysis of common-cause and special-cause variation in the deterioration of transportation infrastructure: a field application of statistical process control for structural health monitoring. Transp. Res. Part B Methodol. (2014). doi:10.1016/j.trb.2013.11.002

Doebling, S.W., Farrar, C.R., Cornwell, P.J.: A statistical comparison of impact and ambient testing results from the alamosa canyon bridge. In: Proceedings of SPIE - The International Society for Optical Engineering (1996)

Gentile, C., Cabboi, A.: Vibration-based structural health monitoring of stay cables by microwave remote sensing. Smart Struct. Syst. (2015). doi:10.12989/sss.2015.16.2.263

Ho, H.N., Kim, K.D., Park, Y.S., et al.: An efficient image-based damage detection for cable surface in cable-stayed bridges. NDT E Int. (2013). doi:10.1016/j.ndteint.2013.04.006

Ju, M., Park, C., Kim, G.: Structural health monitoring (SHM) for a cable stayed bridge under typhoon. KSCE J. Civil Eng. (2015) doi:10.1007/s12205-015-0039-3

Li, H., Ou, J., Zhao, X., et al.: Structural health monitoring system for the Shandong Binzhou Yellow River Highway Bridge. Comput.-Aided Civil Infrastruct. Eng. (2006) doi:10.1111/j. 1467-8667.2006.00437.x 
Liu, S.T., Xiao, H.W., Zhao, Z.Y.: Deflection monitoring of box girders of Hangzhou Bay Bridge. In: Proceeding of International Conference on Health Monitoring of Structure, Materials and Environment (2007)

Naderian, H., Cheung, M.M.S., Shen, Z., et al.: Seismic analysis of long-span cable-stayed bridges by an integrated finite strip method. J. Bridge Eng. (2016) doi:10.1061/(ASCE)BE. 1943-5592.0000821

Ni, Y.Q., Hua, X.G., Fan, K.Q., et al.: Correlating modal properties with temperature using long-term monitoring data and support vector machine technique. Eng. Struct. (2004). doi:10. 1016/j.engstruct.2005.02.020

Ou, J.P.: Some recent advances of structural health monitoring systems for civil infrastructure in mainland China. In: Proceedings of the First International Conference on Structural Health Monitoring and Intelligent Infrastructure, Tokyo, Japan, pp. 131-144 (2003)

Ou, J.: Practical implementations of intelligent health monitoring systems in Hit. In: Ansari, F. (ed.) Sensing Issues in Civil Structural Health Monitoring. Springer, Dordrecht (2005). doi:10.1007/1-4020-3661-2_29

Wei, L., Cheng, H., Li, J.: Modal analysis of a cable-stayed bridge. Procedia Eng. (2012). doi:10. 1016/j.proeng.2012.01.1055

Wong, K.Y.: Instrumentation and health monitoring of cable-supported bridges. Struct. Control Health Monit. (2004). doi:10.1002/stc.33

Xiang, Y.Q., Wang, J.F.: Advance in health monitoring and assessment theory of long span concrete bridge and application. In: Proceeding of 4th China-Japan-US Symposium on Structural Control and Monitoring, Zhejiang University Press, vol. 9, pp. 16-17 (2006)

Xiang, Y.Q., Weng, S.L., Song, Y., Yao, Y.D.: Health monitoring and evaluation management system of Wenhui Bridge. In: Proceeding of First International Conference on Structural Health Monitoring and Intelligent Infrastructure, vol. 11, pp. 13-15 (2003) 